\title{
Development of 'smart'manufacturing in Russia: Empirical region-specific study of system technologies
}

\author{
Evgeniy Starikov, Marina Evseeva $^{1}$, and Irina Tkachenko \\ Ural State University of Economics, 620144 Ekaterinburg, Russia
}

\begin{abstract}
The purpose of the paper is to consider the concept of Industry 4.0 through the prism of 'Factories of the Future' program as a system of integrated technological solutions for creating 'smart' industries. The paper analyzes the TechNet road map proposed by the National Technological Initiative, a program aiming at enhancing the global competitiveness of Russian industry by 2035. Aregion-specific empirical study focuses on system technologies that contribute to the development of 'smart' manufacturing in four industrial regions of Russia: Sverdlovskaya, Chelyabinskaya, Kurganskaya and Tumenskaya Oblasts. The conclusion is made about the upward trendin thedevelopment of 'smart' industries in Sverdlovskaya and Chelyabinskaya Oblasts.
\end{abstract}

\section{Introduction}

A territorial production system at any level can be viewedasa complex of technologies. All technologies can be conventionallycategorizedintobasic, component, and system technologies [1-4]. Basic technologies aretechnologies for the production of materials and other substances (e.g., alloy used for manufacturingaircraft engine turbine blades). Component technologiesare technologies for the production of components and subassemblies that are not products of final consumption (e.g., an aircraft turbine engine).System technology integrates component technologies to produce thefinal product for end users by developing highly engineered mechanisms, machines, and apparatuses(e.g., a passenger aircraft) [5].

Thus, system technologies and related component technologiesare carriers of the most advanced technical solutions; accumulate theintellectual labor of thousands of people, research and development in the field of AdvancedManufacturing Technologies (AMT) whichaccumulate multidisciplinary knowledge and intellectual know-how [6].

A key feature of the current stage of technological development ofterritorial production systems is an overall change by digitalization and automation. The concept of Industry 4.0 as a set of technological changes in manufacturing was coined by the German government in 2011. The main paradigm for automation and data exchange in manufacturing technologies includes the use of the Cyber-Physical Systems whichenable to connect the physical things with virtual models [7]. In Russia, the concept of digital transformation ofthe production

\footnotetext{
${ }^{1}$ Corresponding author: evseevamv@usue.ru
} 
sector through the development and implementation of AMT is applied within the framework of the National TechnologyInitiative (NTI), a program aiming at enhancingthe global competitiveness of Russian industry by 2035 [8].

In this regard, we may hypothesize that a variety of system technologies andlocalization of system integrators in a region maytestify that the processes of digital transformation of the domesticproduction sector and the development of SmartManufacturing are taking place in Russian regions.

System technologies determine the production specialization and competitiveness of the region, since they offer opportunities to manufacture high-tech industrial products with highadded value. At the same time, to ensure the implementation of systemtechnologies,component technologies develop with a multiplicative effect. Component technologies may also contribute to gaining territorial competitive advantage by establishingnew component manufacturing with a high level of employment based on theintroduction of new engineering and manufacturing solutions and the development of newproducts. The development of basic technologies is largely due to the presence andcomposition of local mineral resource base. The growth of systemtechnologies used in the region prompts the correspondinggrowth of component technologies. Thus, varioustechnologies and localization of system integrators is a factor that maintains stability and competitiveness of regional industries. This results from possible engineering integration along global technological chains and visual effect of diversification: the territory retains its economicstability even if a product manufactured with the use of a particular technology is not in demand. On the contrary, the dominance of a technology (evenif there are many system integrators) is the factor thatmakes regional economy more sensitive to market fluctuations.

The NTI TechNet roadmap introduces the concept of FactoriesoftheFuture(FoF), FoF are understood as systems of integratedtechnological solutions (in fact, integrated technologicalchains) that enable to design and manufacture anew generation of globally competitive productsin the shortest possible time. The TechNetroadmap suggests a classification of FoFon the basis of leading groups of technologies: DigitalFactories, SmartFactories and Virtual Factories. DigitalFactoriesare charged with the task of designing manufactured products by using software, digital design and modeling tools. SmartFactoriesrefer to flexible production facilities with awide application of Process Automation Systems (PAS) and planning systems based on robotic processes. The combination of these technologies is aimed at increasing an overall level ofintellectualization and production efficiency, increasing faulttolerance, and creating the basis for further development of new markets forinnovative manufacturing solutions. Finally, VirtualFactories is anaggregator thatconnectsall parties into a single logistics chain: consumers of high-tech products, manufacturers, designers andprogrammers of production software (Digital Factories), facilities for components production; assembly and final product manufacturing using themost advanced technologies (Smart Factories), as well as suppliers of materials. Creation and scale application of technological solutions proposedin the TechNet roadmap are aimedat developing and increasing the export potential of the domestic industry, aswell as at resolving the issue of substituting imported high-tech products through the use of advanced production technologies [9].

It has been witnessed that some sectors of the Russian economy conform to international standards with regard to the degree of digitalization (e.g., finance, state and municipal services, education). At the same time, the manufacturing sector cannot meet theinternational standards of digitalizationand application of advanced technologies. Nevertheless, in recent years many regions have startedmodernizing the existing production facilities and building new 'smart' capacities which integrate computer high-precision and information components with high-performance labor and create cooperative chains, territorialmanufacturing and technological clusters. Surveys show that $78 \%$ of Russian large companies' management 
considerdigital transformation to be their priority for the next 3-5 years, whichcertainly gives grounds for optimistic forecasts of the manufacturing sector growth in Russia in Industry4.0 [10].

\section{Methods and results}

An empirical study of system technologies was conducted for four legal entities within the Ural Federal Okrug: Sverdlovskaya Oblast, Chelyabinskaya Oblast,KurganskayaOblestand Tyumenskaya Oblast(autonomous okrugs excluded). The choice of the manufacturing sectoras the subject of study is determined bythe pronounced industrial type of these regions' economies: a significant share of thegross regional product is formed by processing industries.

To identify the totality of technologies implemented in the regions, disaggregation of the Russian National Classifier of Types of Economic Activity (OKVED-2) codes has been applied. We understand a type of economic activity as a combination of similar technologies, which results in a final product or a product for intermediate consumption. Given this provision, we have detailed the OKVED-2 codes to the levelof a single technology.For example, production of air and space craftand relatedequipment (OKVED-2 code 30.3) includes system technologies (manufacturing of aircraft; helicopters; unmanned systems and flight hardware;launch test vehicles; artificial satellites,planetary probes, orbital stations, shuttles etc.) and component technologies (production of components for aerial vehicles; fuselages, wings, doors, pitch attitude control fins; control wheels; chassis, fuel tanks; open cockpits;,aircraft motors and engines; components for turbojet and turbopropaircraft; equipment for launch complexes for rockets and spaceship).

The sample includes three types of companies: system technologyintegrators; component technology integrators; and basic technology integrators. Technological affiliation of the company was determined by its core economic activity.SPARK-Interfax was used to verify the study sample (Table 1). The observation periodis 12 years, from 2007 to 2019.

Table 1.The study sample (2019)

\begin{tabular}{|l|c|c|c|c|}
\hline \multicolumn{1}{|c|}{ Factor } & $\begin{array}{c}\text { Kurganskaya } \\
\text { Oblast }\end{array}$ & $\begin{array}{c}\text { Tumenskaya } \\
\text { Oblast* }\end{array}$ & $\begin{array}{c}\text { Sverdlovskaya } \\
\text { Oblast }\end{array}$ & $\begin{array}{c}\text { Chelyabinskaya } \\
\text { Oblast }\end{array}$ \\
\hline General totality $(N)$ & 290 & 541 & 1673 & 1468 \\
\hline Sample companies $(N)$ & 144 & 255 & 865 & 859 \\
\hline $\begin{array}{l}\text { Aggregated market } \\
\text { share by profit }(\%)\end{array}$ & 85.5 & 83.6 & 86.0 & 86.3 \\
\hline $\begin{array}{l}\text { Identified basic } \\
\text { technologies }(n)\end{array}$ & 8 & 12 & 37 & 31 \\
\hline $\begin{array}{l}\text { Identified component } \\
\text { technologies }(n)\end{array}$ & 26 & 38 & 101 & 86 \\
\hline $\begin{array}{l}\text { Identified system } \\
\text { technologies }(n)\end{array}$ & 8 & 11 & 72 & 24 \\
\hline
\end{tabular}

*Autonomous okrug excluded

The next step was to calculate Shannon andSimpson indices for each region, which are used to measure diversity ofobjects in a limited population (Table 2). Shannon Index (Eq. 1) characterizes the diversity and alignment of objects in thepopulation. Simpson Index (Eq. 2) 
indicates the dominance of certain objectsin the aggregate. The combination of these indices is believedto most fullycharacterize the measure of diversity[11].

$$
\begin{aligned}
& H=-\left(p_{i} / p \cdot \ln \left(p^{i} / p\right)\right) \\
& D=\left(\Sigma p_{i}\left(p_{i}-1\right)\right) / p(p-1)
\end{aligned}
$$

where $p_{i}=i$ technology integrators;

$p=$ total companies;

$n=$ total technologies by type

The obtained data can beinterpreted as follows:

1)The more technologies in the region's industrial sector and the less variable the number of the companies integrating these technologies, the higher Shannon Index. With a small diversity of technologies, Shannon Index tendsto zero.

2)The more pronounced the dominance of a technology (see number of technology integrators), the higher Simpson Index. With a uniform distribution of technology integrators, Simpson Index tends to zero.

Table 2.Calculated Shannon and Simpson Indices

\begin{tabular}{|l|c|c|c|c|}
\hline \multicolumn{5}{|c|}{ Shannon Index } \\
\hline & 2007 & 2011 & 2015 & 2019 \\
\hline Sverdlovskaya Oblast & 5.01 & 6.12 & 5.78 & 5.81 \\
\hline Tumenskaya Oblast* & 3.36 & 3.40 & 3.67 & 4.32 \\
\hline Chelyabinskaya Oblast & 5.36 & 5.61 & 5.62 & 5.69 \\
\hline Kurganskaya Oblast & 3.58 & 3.50 & 3.51 & 3.33 \\
\hline \multicolumn{5}{|c|}{ Simpson Index } \\
\hline Sverdlovskaya Oblast & 0.112 & 0.110 & 0.091 & 0.084 \\
\hline Tumenskaya Oblast* & 0.43 & 0.41 & 0.32 & 0.36 \\
\hline Chelyabinskaya Oblast & 0.093 & 0.092 & 0.097 & 0.081 \\
\hline Kurganskaya Oblast & 0.21 & 0.22 & 0.27 & 0.28 \\
\hline
\end{tabular}

*Autonomous okrug excluded

According to the 2019 data, most system technologies were used in Kurganskaya Oblast (19\% of the total), followed by Tumenskaya Oblast (18\%) and Chelyabinskaya Oblast(17\%). The share of system technologies implemented in Sverdlovskaya Oblast was the lowest and accounted for $14 \%$. However, the number of implemented system technologies has been increasing steadily in Sverdlovskayaand Chelyabinskaya Oblasts, as can be seen in Fig. 1. 


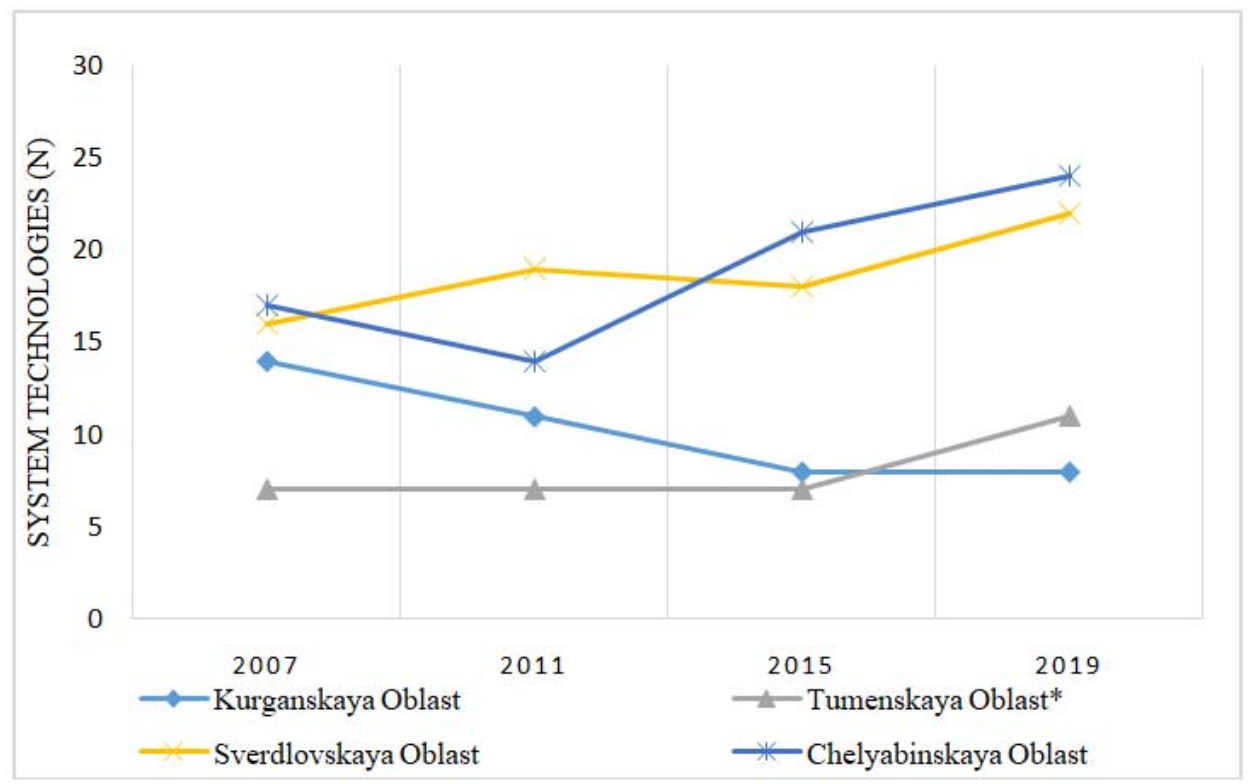

Fig. 1. System technologies implemented in the studied regions.

For each group of companies Total Factor Productivity was found. It measures productivity growth and has become a proxy for technological progress.A state-of-the-art measure of TFP is given by the following formula (Eq.3):

$$
T F P=(Y / K) \alpha /(1-\alpha)
$$

where $Y=$ total output;

$K=$ capital input;

$L=$ labout input;

$A=$ total factor productivity;

$\alpha=$ perspective share of output $(=0.3)$.

\section{Discussion}

By and large, diversity indices for Sverdlovskaya and Chelyabinskaya Oblasts arecomparable in terms of value and show a similar trend toward an increasing diversity of technologies. A number of system integrators in these two regions is growing. Currently, 144 system integrators are located in Sverdlovskaya Oblast (Fig. 2) and 132 in Chelyabinskaya Oblast. However, at all technological levels we observe the smallest variance of TFP, which indicates a lowfragmented inter-firm environment. A free flow of resourcescontributes to more even distribution and localization of technologies in the mostproductive companies. 


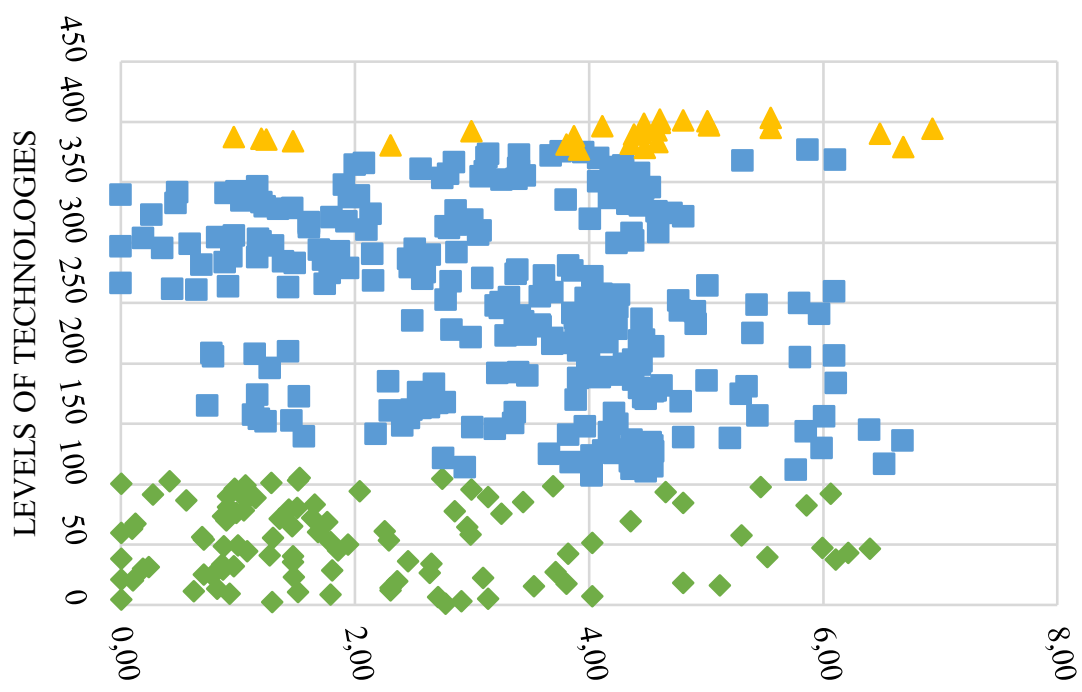

$\Delta$ Basic technologies Component technologies $\triangle$ System technologies

LN TFP

Fig. 2.TFP of firms located in Sverdlovasksys Oblast (2019)

As it was expected, the manufacturing sector of Tumenskaya Oblast has the highest Simpson index, which proves the presence of the dominant technology that forms a vector of development of the regional manufacturing sector and reduces itsresistance to market fluctuations. The component integrator groupincludes the firms producing constitutive elements for the dominantsystem technology. However, we can observe a downward change in Simpson Index, whichindicates that other system and component technologies emerge in the region. It is worth noting that during the entire observation period,system integrators in Tumenskaya Oblast showed the highest TFP.

Kurganskaya Oblast is also characterized by high Simpson Index and lowvalues of Shannon Index. This proves a small variety oftechnologies and the presence of a dominant technology. However, on the one hand, a downward trend is observed since the range of technologies is narrowing. On the other hand, component technologies do not match the profile of systemtechnology. This exacerbates areduction in gross value added,generated by system integrators.

For Tumenskaya, Sverdlovskaya and Chelyabinskaya Oblasts TFP in the group of system integrators is higher than inthe groups of basic technology and component integrators. TFP levels in Kurganskaya Oblast are comparable along all three groups and are similar to basic technology productivity in Chelyabinskaya and Sverdlovskaya Oblasts. In general, system technologies create higher added value.

However, we argue that the more system technologiesimplemented in the region, the greater the gap inTFP levels in the system andcomponent technologies. The variety of technologies in the system and component groupscontributes to higher gross value added generated bysystem integrators.

\section{Conclusions}

Thus, the analysis of technological development of the manufacturing sectors and the establishment of system integrators in four regions of Russia shows that the most dynamicprocesses of creating 'smart' industries based on system technologies take place in Sverdlovskaya and Chelyabinskaya Oblasts. Localization of system integrators in these regions, a significant variety of system technologies and, as a result, the formation of supporting groups of component technologies, provide multiplicative integrated development of the industrial sector in these regions based on scaling up modern 'smart' industries. This smart manufacturing can generate high added value, which, in turn, might attract 
additional funds and high-skilledhuman resources. This will ensure economic stability and a high level of regional competitiveness.

\section{References}

1. C.W.I. Pistorius, J.M. Utterback, Research Policy, 26 (1), 67 (1997)

2. $\quad$ N. Meade, T. Islam, Management Science, 44(8), 1115 (1998)

3. S.J. Lee, D.J. Lee, H.S.Oh, Technological Forecastingand Social Change, 72 (8), 1044 (2005)

4. G. Zhang, D.A. McAdams, V. Shankar, M.M. Darani, Technological Forecasting and SocialChange, 125, 116(2017)

5. G. Zhang, D. Allaire, V. Shankar, D.A. McAdams, PLoS ONE, 14(6), e0218370 (2019)

6. N.V. Vasilenko, K.V. Kudryavtseva, Digital transformation of the economy and industry: problems and prospects, 67 (2017)

7. S.I. Tay, T.C. Lee, N.A.A. Hamid, A.N.A. Ahmad. Jour of Adv Research in Dynamical \& Control Systems, 10 (14), 1379 (2018)

8. A.V. Babkin, D.D. Burkaltseva, D.G. Kosten, Yu.N. Vorobiev. Scientific and technical statements of the St. Petersburg State Polytechnic University.Economic sciences.3 (10), 9 (2017)

9. I.A. Gunina, E.V. Shkarupeta, V.V. Reshetov, Innovative clusters of the digital economy (2018)

10. I.N. Tkachenko, E.N. Starikov, Izvestiya of Saratov University. New series. Series: Economics. Management. Law, 3(20), 244 (2020)

11. M.V. Evseeva, Journal of New Economy, 3(21), 132 (2020) 